TOPICAL REVIEW • OPEN ACCESS

\title{
Ecological illiteracy can deepen farmers' pesticide dependency
}

To cite this article: K A G Wyckhuys et al 2019 Environ. Res. Lett. 14093004

View the article online for updates and enhancements. 


\section{Ecological illiteracy can deepen farmers' pesticide dependency}

\section{OPEN ACCESS}

RECEIVED

17 March 2019

REVISED

22 July 2019

ACCEPTED FOR PUBLICATION

23 July 2019

PUBLISHED

6 September 2019

Original content from thi work may be used under the terms of the Creative

Commons Attribution 3.0

licence.

Any further distribution of

this work must maintain

attribution to the

author(s) and the title of

the work, journal citation

and DOI.

\author{
K A G Wyckhuys ${ }^{1,2,3,4}{ }^{\oplus}, \mathrm{K} \mathrm{L} \mathrm{Heong}^{1}$, F Sanchez-Bayo ${ }^{5}$, F J J A Bianchi ${ }^{6}$, J G Lundgren ${ }^{7}$ and J W Bentley ${ }^{8}$ \\ 1 Zhejiang University, Hangzhou, People's Republic of China \\ 2 University of Queensland, Brisbane, Australia \\ 3 China Academy of Agricultural Sciences, Beijing, People's Republic of China \\ 4 Chrysalis Consulting, Hanoi, Vietnam \\ 5 University of Sydney, Sydney, Australia \\ 6 Farming Systems Ecology, Wageningen University \& Research, Wageningen, The Netherlands \\ 7 Ecdysis Foundation, Estelline, SD, United States of America \\ 8 AgroInsight, Cochabamba, Bolivia \\ E-mail:kagwyckhuys@gmail.com
}

Keywords: social-ecological systems, sustainable intensification, ecological knowledge systems, agricultural anthropology, behavioral change, agro-chemical pollution

Supplementary material for this article is available online

\section{Introduction}

The Anthropocene is posing extraordinary social, economic and environmental challenges for humanity: extensive chemical pollution, biocide resistance, habitat destruction and biodiversity loss are major threats that are further compounded by climate change (Maxwell et al 2016, Bernhardt et al 2017, Jørgensen et al 2018). The 2030 UN Sustainable Development Goals of ending poverty and achieving sustainable food and nutritional security without depleting natural resources (Stafford-Smith et al 2017) recognize the role that biodiversity can play in bolstering ecosystem functioning and stability (Isbell et al 2017). Agriculture-occupying 50\%-60\% of arable land worldwide-is at the core of addressing these challenges, and its sustainable intensification offers a synergistic way to meet food production targets while conserving natural capital (Pretty et al 2018). Given the close two-way interaction between agriculture and the delivery of ecosystem services (Smith and Sullivan 2014), the contribution of the world's approx. 2.5 billion smallholder farmers to societal wellbeing can be immense and transformative.

Ecosystem services, such as biological control of herbivores, are central to the sound functioning of the world's ecosystems and to a sustained production of food and agricultural produce. Yet, despite their proven economic value and societal benefits (Losey and Vaughan 2006), they are often disregarded and 
substituted by chemically-synthesized inputs such as fertilizer or insecticides (Bernhardt et al 2017, Jørgensen et al 2018). Aside from being costly and oftentimes superfluous, insecticides contribute to biodiversity loss, help push beneficial organisms beyond 'safelimit' thresholds and undermine ecological resilience (Krebs et al 1999, Oliver et al 2015, Huang et al 2018, Sánchez-Bayo and Wyckhuys 2019). Yet, in the face of a surging use of pesticides (Bernhardt et al 2017, Jørgensen et al 2018), pest-related yield losses in global agriculture continue to be substantial and farm-level profitability has not increased (Oerke 2005, Lechenet et al 2017, Deutsch et al 2018). To remediate farmers dependency upon agro-chemicals and to alleviate their associated burden on biodiversity, ecosystem functioning and human health, a solid understanding is required of potential pest species and their antagonists, which is the foundation for Integrated Pest Management or IPM (Ehler 2006), in combination with a holistic, interdisciplinary perspective and due inclusion of social science (Winarto 2004, Cui et al 2018, Flandroy et al 2018, LaCanne and Lundgren 2018, Pretty et al 2018).

While farmers' management behavior is complex and influenced by a wide range of factors (Mills et al 2017, Zhang et al 2018), it is integrally shaped by their knowledge, attitudes and beliefs (Heong and Escalada 1999, Lamarque et al 2014, Mills et al 2017). Local biological knowledge -a non-commoditized form of information possessed by any culture- underpins management decision-making, but can be esoteric, context-specific and incomplete (Bentley 1993, Brush 1993, Gurung 2003). Differing from scientific knowledge, folk or 'traditional' knowledge is generated through observation, encompasses environmental and social learning processes that constitute 'agricultural skilling' and results in culturally-compatible, resource-conserving practices (DeWalt 1994). Such biological knowledge contains ancient ecological experiences and perspectives accumulated over the course of multiple generations (Berkes et al 2008).

Cognitive anthropologists have captured the oftensophisticated knowledge of beneficial arthropods among indigenous folk and tribal people (Berlin 1992), and ethno-entomologists have uncovered their indepth understanding and classification of social wasps or ants (Posey 1984). Others have described peasants' knowledge systems primarily in the developing-world tropics (Morales and Perfecto 2000, Bentley and Rodríguez 2001, Ulicsni et al 2016), and revealed how knowledge is regularly constrained to culturally-important and easily-observed organisms. Also, incipient work has shown how farmers' perception of ecosystem services is linked to their agroecological management at the farm level (Teixeira et al 2018). Here we define ecological literacy as the ability to understand the organization and functioning of natural systems, and the principles to manage agroecosystems based on natural processes, such as the top-down suppression of pests by natural enemies (e.g. Van Mele 2008). Yet, no global systematic assessment has been made of farmers' appreciation of insect-mediated ecosystem services and its link to crop protection-the essential premise for sustainable intensification.

In this review, we illustrate how farmers' ecological knowledge influences their farm management decisions, as related to pest management. Drawing upon published ethnobiology and anthropology surveys and agricultural entomology studies, we describe global patterns in farmers' understanding of ecosystem-service and disservice-providing arthropods (i.e. natural enemies, crop pests respectively). First, we contrast overall patterns in arthropod knowledge between indigenous people and contemporary farmers. Second, we describe the ecological literacy of farmers globally, including their appreciation of herbivores, pests and natural enemies. Third, we relate local ecological literacy to pest management decision-making and farmers' adoption of biological control. Our work intends to uncover levels of ecological illiteracy among the world's farming populace, and examine how this can hamper the diffusion of ecologicallybased management and slow a global transition to sustainable intensification of agriculture.

\section{Methods}

\section{Literature review and data processing}

As a first step in our assessment, we conducted a nonexhaustive review of the global literature in ethnobiology, agricultural anthropology, environmental psychology, pest management science and related fields. We restricted our literature search to peerreviewed publications that were published between 1900 and 2017, and paid particular attention to studies that described patterns in indigenous or folk knowledge of arthropods (including herbivores, crop pests or insect-consuming organisms) in rural settings and specifically in agricultural or forestry crops, and associated decision-making processes related to crop protection. A core set of papers was consolidated by using different combinations of the following search terms: 'pest ${ }^{*}$, ' 'insect', 'farmer', 'rural', 'folk', 'natural enem*, 'arthropod*', 'crop protection', 'pesticide', 'agricult", and by further screening the references therein (supplementary tables 1, 2 is available online at stacks.iop.org/ERL/14/093004/mmedia). Google Scholar (GS) was used as a search engine to extract relevant records from the global scientific literature, running queries between October 1 and November 6, 2018. For each record, key socio-economic, agronomic and geographical information was extracted.

The compiled dataset was divided into three subsets of publications. A first set of records covered 
comprehensive ethnobiology surveys to unveil the ecological knowledge of indigenous folk, tribal people and farmers (supplementary table 2), and specifically the extent of folk knowledge of invertebrates that locally occur within agricultural crops and non-crop habitats. For each literature record, we logged the specific methods that were employed for cultural domain analysis (Russell 2002), and extracted the full set of invertebrates that were enumerated by local informants. For each record, we noted the total number of described species or locally-assigned names (i.e. ethno-categories) per arthropod family in the established scientific taxonomic hierarchy. Next, the number of listed or recognized species (or ethnocategories, defined as biological classification categories by ethnic groups) was averaged across studies at different taxonomic hierarchies, i.e. family, superfamily or order, and compared with the total number of scientifically-described species at this respective hierarchy. As published studies employed different diagnostic methods to elicit informants' knowledge, we exclusively considered studies that used free-listing for comparative purposes.

A second set of records comprised entomology or agricultural anthropology studies that either covered (1) farmers' knowledge of herbivorous arthropods associated with a particular crop or cropping system, which do not necessarily require control (or 'neutral species'), (2) farmers' listing of arthropods as economicallyimportant herbivores that were targeted in control measures, referred to as 'pests', and (3) farmers' recognition or free-listing of arthropod biological control organisms or so-called natural enemies (supplementary table 1). For either of the above groups, we logged the exact proportion of farmers (within a given study) that listed a particular organism per arthropod family. For studies that compared agro-ecological knowledge between IPM trained and untrained farmers, we solely extracted information for untrained ones as to best capture farmers' baseline knowledge. Despite eventual limitations of the original studies, we tried to gauge farmers' knowledge in a comprehensive manner. Extent of farmer knowledge was either computed per study by averaging taxon-specific measures across taxa, or per taxon by averaging the above measures across studies for a specific taxonomic hierarchy. We hereby used the number of species enumerated by farmers as an indicator of ecological literacy (see the following) For each study, we also recorded the total number of taxonomic hierarchies (i.e. order or family) within which organisms were listed. To reflect the hierarchy in farmers' enumeration of herbivorous arthropods (at two taxonomic levels) and economically-limiting pests, a sunburst diagram was constructed.

A third set of records included a broader set of studies in the fields of agronomy, crop protection or social science, in which detailed (taxon-specific) entomological knowledge was often missing. Records yielded a heterogeneous set of metrics that reflected farmers' agro- ecological knowledge, including their awareness and perceived importance of agricultural pests and natural enemies, and associated pest management decisionmaking. Where appropriate and possible, metrics were re-scaled and adapted to attain a standardized measure as follows: perceived importance among farmers of insect pest damage (0-1), general farmers' awareness of natural enemies (0-1), number of non-chemical pest management tactics listed per informant, local extent of usage of non-chemical alternatives (0-1), and the degree of primary reliance upon synthetic insecticides (0-1). Here, for comparative purposes, studies in which the number of crop pests or natural enemies was listed were only taken into consideration if such knowledge was acquired through free-listing (or if its use was inferred, when not explicitly described in the study methodology). For studies in which non-chemical crop protection alternatives were enumerated, those were compiled and organized in relevant sub-categories (e.g. mechanical control, cultural control). Any practices that are either superstitious, ego-centric (i.e. praying; Miller 1983) or well-recognized to be ineffective were excluded from the analyses.

\section{Ecological literacy metrics}

To capture the heterogeneity in the measures of farmers' agro-ecological knowledge available in the literature, a twin metric of ecological literacy was developed for each of the three groups of organisms: neutral herbivorous species, economically-important target pests, and arthropod natural enemies. Metrics were built around the concept of salience (or 'awareness'), which captures shared entomological knowledge or the proportion of farmers within a given study that freelisted arthropods within a particular taxon. Salience measures were either computed for a given taxon (i.e. arthropod family or order) by averaging respective metrics across studies or summed across taxa to generate an overall measure of salience for a given study. Salience of a given arthropod taxon (as averaged across studies) or for a given study (as averaged across farmerlisted taxa) was exclusively computed for organisms that were listed by at least one farmer, i.e. zeros were omitted in the calculation. Per study, agro-ecological literacy was thus reflected by: (1) the summed salience of farmer-listed arthropods at a pre-defined taxonomic hierarchy, i.e. family or order; and (2) the total number of farmer-listed arthropod taxa. For ease of presentation, the former salience metric was occasionally converted to percentages.

\section{Statistical analyses}

Statistical analyses were carried out to compare farmers' ecological literacy-i.e. averaged salience and total number of listed taxa - or particular metrics reflective of farmer knowledge and pest management behavior between cropping systems (i.e. staple crops versus cash crop/mixed systems). More specifically, One-way 
Analysis of Variance (ANOVA) was used on normally distributed data-sets while non-parametric tests (i.e. Mann-Whitney U) were employed for the remainder. Where necessary and feasible, data were log-normal transformed to meet assumptions of normality and homoscedasticity, and all statistical analyses were conducted using SPSS (PASW Statistics 18).

\section{Results}

\section{Sampling universe}

For the characterization of ecological literacy and pest management behavior, a non-exhaustive literature search yielded 73 peer-reviewed studies and an associated 80 records of distinct crop or geographical focus. Records comprised survey work conducted between 1910 and 2016 (median year of publication: 2005), with 10\%, 25\%, 39\% and 26\% from Europe, Americas, Asia/Oceania and Africa, respectively. Surveys primarily relied upon person-to-person questionnaires (using free-listing, photo-elicitation and specimen description as popular ways to gauge extent of knowledge) and covered a total of 12,000 informants, primarily farmers and rural people. This sampling universe was highly skewed towards developing countries in tropical climes, covering $1 \%$ informants from Europe, 32\% from Americas, 29\% Asia/Oceania and 38\% from Africa. Most work was carried out in the Philippines $(n=9)$, followed by Iran $(n=5)$ and Brazil $(n=4)$. While $44 \%$ of records covered staple crops ( $n=19,14$ respectively for rice and maize), the remaining ones included either cash crops, mixed systems or unspecified crops. The studied systems were characterized by a farm size of $42.8 \pm 97.3$ ha (mean $\pm S D ; n=34$; median: 2.9 ha), and informants were $73.0 \pm 18.9 \%$ male farmers $(n$ $=21), \quad 46.4 \pm 10.1$ years of age $(n=31)$ and $65.6 \pm 28.3 \%(n=18)$ possessing formal education. Among the interviewees, $76.4 \pm 14.5 \%(n=15)$ were landowners.

For the assessment of overall trends in arthropod knowledge among indigenous folk and rural people, a smaller set of 15 publications was consulted. This set comprised studies from Europe (6.7\%), Americas (60.0\%), Asia/Oceania (20.0\%) and Africa (13.3\%); with 14 of these covering mixed farming systems.

\section{General insect knowledge patterns}

Out of 51 arthropod taxa comprising over 1 million scientifically-described species across ecosystems (Stork 2018), informants either recognized or named an average of 157.8 organisms or ethno-categories, or $0.013 \%$ of described arthropods (supplementary figure 1). Across studies, informants' breadth of knowledge was of 49 individual organisms or ethnocategories within 10 (median) established orders. Extensive knowledge was recorded for the Dogon ethnic group in Mali (825 organisms or ethno- categories), the Baniwa and Kapayo Indians in the Amazon (306 and 264 organisms, respectively) and rural people in Honduras (213) and Europe's Carpathian Basin (271) (Griaule 1961, Posey 1984, Petiza et al 2013, Ulicsni et al 2016).

Knowledge was most extensive for 'membranewinged' insects or Hymenoptera (48.5 \pm 57.7 listed organisms; median: 28.5), grasshoppers, crickets and locusts under the Orthoptera $(19.5 \pm 28.6$; median: $8)$, beetles or Coleoptera (37.4 \pm 65.4 ; median: 17$)$, and true bugs or Hemiptera (21.3 \pm 24.3 ; median: 8). Some studies revealed substantial folk knowledge of certain taxa: the Dogon in Mali possess 100 different names for grasshoppers (Griaule 1961), the Kapayo Indians in the Brazilian Amazon have 211 different names for wasps, bees and ants (Posey 1984). Within a given arthropod order, informants' ability to list or recognize species varied considerably between subtaxa (e.g. superfamily, infra- or sub-order) (figure 1). Informants were most knowledgeable about sphecoid wasps and bees (Apoidea) and wasps (Vespoidea) (Order Hymenoptera; 18.3 and 37.3 respective species or ethno-categories), scarab beetles (Scarabaeoidea) and the long-horned and leaf-beetles (Chrysomeloidea) (Order Coleoptera; 10.0 and 5.3 listed), Noctuioidea and Bombycoidea (Order Lepidoptera; 5.8 and 2.9 listed), and mosquitoes and blackflies (Culicomorpha) and blow flies or bot flies (Oestroidea) (Order Diptera; 3.8 and 2.1 listed).

Within the above respective orders, average informants' knowledge thus covered $0.039 \%, 0.010 \%$, $0.010 \%$ and $0.008 \%$ of described insect fauna. Considerable variability was recorded in the depth and breadth of arthropod knowledge, with surveys showing relatively extensive knowledge of Mali tribal people of dung beetles (Scarabeidae), ants (Formicidae) among Indian tribes in the Amazon and social wasps (Vespidae) among Honduran campesinos (supplementary figure 2).

\section{Farmers' understanding of insect herbivores and pests}

Across published studies, contemporary farmers reported different species of herbivores to occur within their crop, belonging to $4.1 \pm 2.0$ orders of arthropods and $1.2 \pm 1.6$ non-arthropod taxa $(n=29$ studies). Arthropod orders that were widely recognized by farmers include Lepidoptera $(32.5 \pm 24.8 \%$ farmers; $n=40)$, Thysanoptera $(25.9 \pm 22.1 \%$; $n=4)$ and Hemiptera $(25.1 \pm 16.3 \% ; n=23)$. Within those respective orders, the most salient families are Pyralidae (49.3\%), Crambidae (34.8\%) and Noctuidae (34.2\%); Alydidae (75.6\%), Pyrrhocoridae (39.7\%) and Pseudococcidae (27.8\%) (figure 2). Non-arthropod herbivores that were regularly enumerated included birds (30.6\%; $n=6$ studies) and rodents $(33.6 \% ; n=9)$. Nematodes were only mentioned by $8.7 \pm 1.7 \%$ farmers $(n=2)$. 

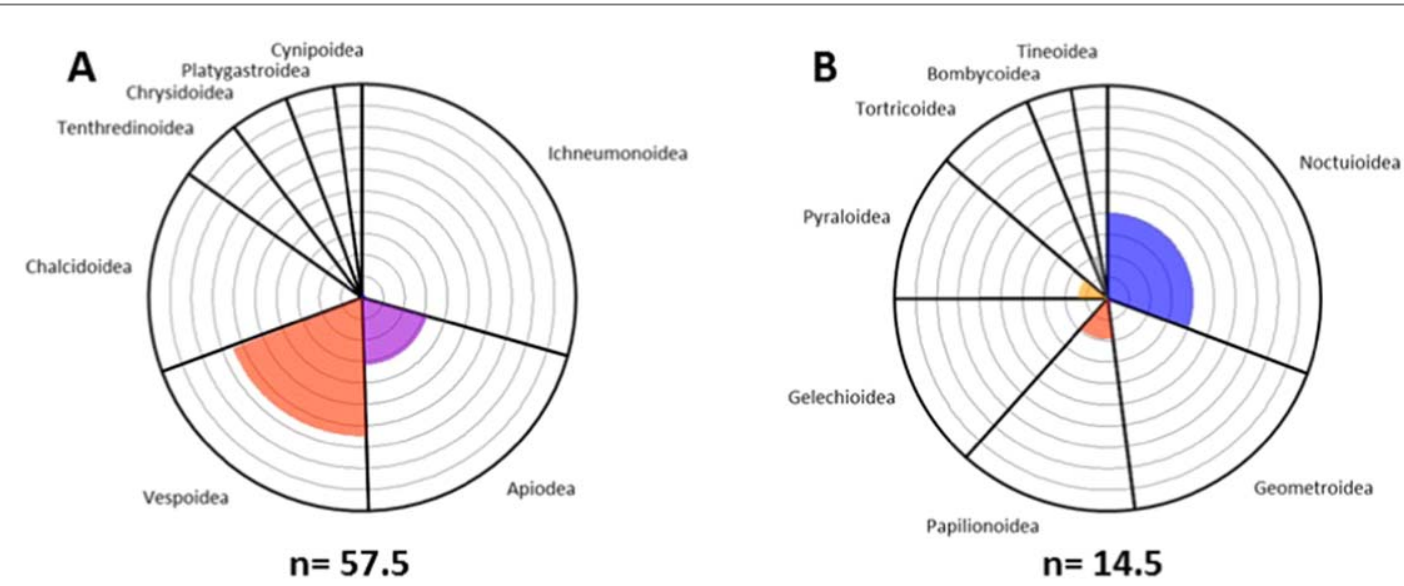

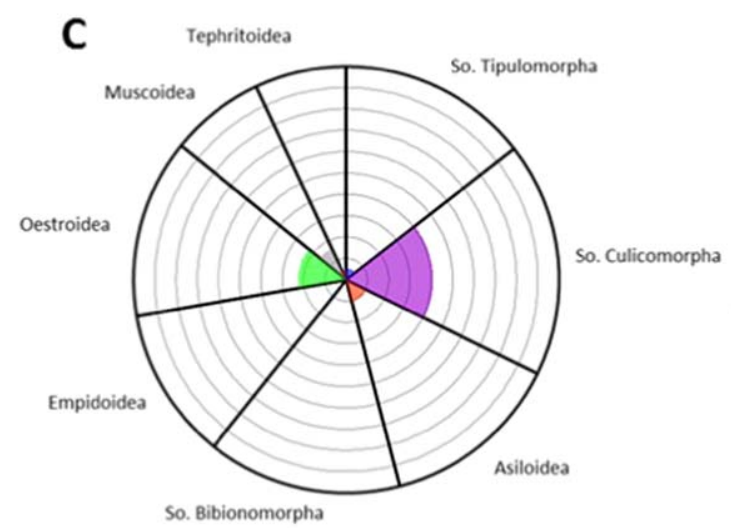

$n=9.3$

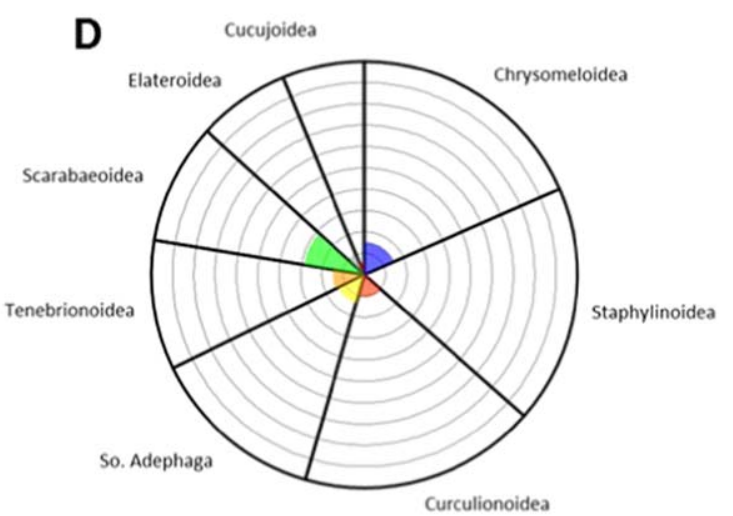

$\mathrm{n}=\mathbf{3 4 . 9}$

Figure 1. Ecological knowledge of farmers, indigenous folk and rural people is confined to few conspicuous, culturally-important taxa. Within each diagram, comparative extent of informants' knowledge is shown for the eight most speciose taxa within 4 insect orders: Hymenoptera ((A); 150000 described spp. across ecosystems), Lepidoptera ((B); 157338 spp.), Diptera ((C); 155477 spp.), and Coleoptera ((D); 386500 spp.). Depicted insect super-families or suborders (So.) represent 71\%-98\% described species within their respective order, with relative abundance of a given family reflected by the section of the pie chart. Within a given order, the average number of recognized or freely listed taxa is indicated in the following its respective pie chart, and its relative distribution across insect families is represented by the different colour-coded pie sections. Extent of informant knowledge was gauged through various approaches in 15 published studies_-including free-listing, photo-elicitation and specimen description.

In staple crops, farmers enumerated herbivores belonging $4.5 \pm 2.3$ different orders ( $n=15$ studies). More specifically, in rice systems, listed herbivores belong to $3.0 \pm 1.0$ orders ( $n=3$ studies), with Lepidoptera $(29.8 \pm 15.9 \%$ farmers; $n=6)$ and Hemiptera $(45.8 \pm 15.7 \% ; n=3)$ the most salient orders. In maize systems, listed herbivores belong to $3.8 \pm 2.6$ orders ( $n=6$ studies), with Lepidoptera (42.2 \pm $24.2 \%$ farmers; $n=12)$ and Coleoptera (22.8 \pm $21.1 \% ; n=6$ ) being the most salient orders. Lastly, in cash crop and mixed systems, listed herbivores belong to $4.3 \pm 1.7$ orders ( $n=14$ studies), with Isoptera (46.3 $\pm 48.4 \%$ farmers; $n=3)$, Thysanoptera (44.8 \pm $3.9 \% ; n=2)$ and Lepidoptera $(29.8 \pm 26.5 \% ; n=18)$ being the most salient orders. The extent to which farmers enumerated arthropod herbivores at the order level did not statistically differ between the two main crop types. Average order-level saliency or farmer 'awareness' was $26.0 \pm 17.1 \%$ ( $n=29$ studies $)$, ranging from an average of $3.8 \%$ amongst Cameroon vegetable growers that enumerated herbivores at the order level (Abang et al 2014), to $69.7 \%$ in Nigeran farmers that listed herbivores belonging to a total of 5 arthropod orders (Atteh 1984).

In 15 studies, farmers specifically described herbivorous organisms as economically-important pests and targets of control interventions. Control targets comprised different herbivores, belonging to $3.0 \pm$ 1.0 orders of arthropods and $0.5 \pm 0.9$ non-arthropod taxa. Perceived pest targets commonly belonged to Lepidoptera $(28.6 \pm 27.8 \%$ farmers; $n=28)$ and Hemiptera $(23.6 \pm 23.7 \% ; n=12)$. Within those respective orders, the most salient families are Gelechiidae (38.5\%), Noctuidae (33.8\%) and Pyralidae (32.3\%); Pentatomidae (71.0\%), Alydidae (44.6\%) and Aleyrodidae $(33.0 \%)$ (figure 2). Non-arthropod organisms that were regularly enumerated as pests included birds (40.2\%; $n=2$ studies), while nematodes were only mentioned by $4.0 \%$ farmers in one study. The extent to which farmers enumerated arthropod pests at the order level did not statistically differ between staple crops and cash/mixed crop systems. 


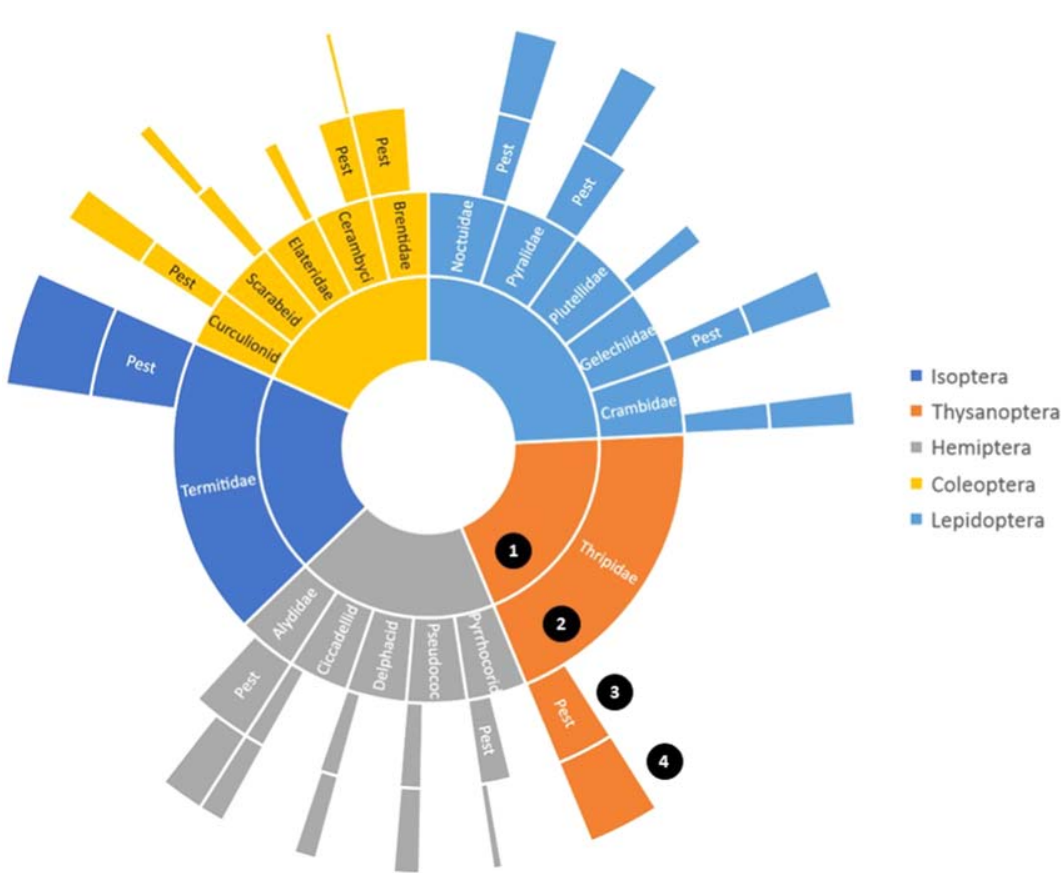

Figure 2. Farmers possess scant knowledge of herbivorous arthropods and agricultural pests. A sunburst diagram visualizes the hierarchy of farmers' ranking of agricultural pests, covering 5 insect orders and consisting of concentric rings sliced according to different categories. From the innermost ring outward, categories represent: (1) perceived importance of a given insect order, in terms of it containing key herbivores including pests targets; (2) up to 5 insect families that are perceived as key herbivores; (3) percent farmers that free-list herbivores belonging to a given family; (4) percent farmers that perceive particular herbivores as pests, deliberately targeting them in management interventions. Data are compiled from 29 published studies for herbivore ranking, and 15 studies for pest target enumeration, with the diagram solely representing the 5 insect orders of greatest concern to farmers. Salience of a given arthropod taxon is based upon studies in which organisms are either free-listed or identified through photo-elicitation.

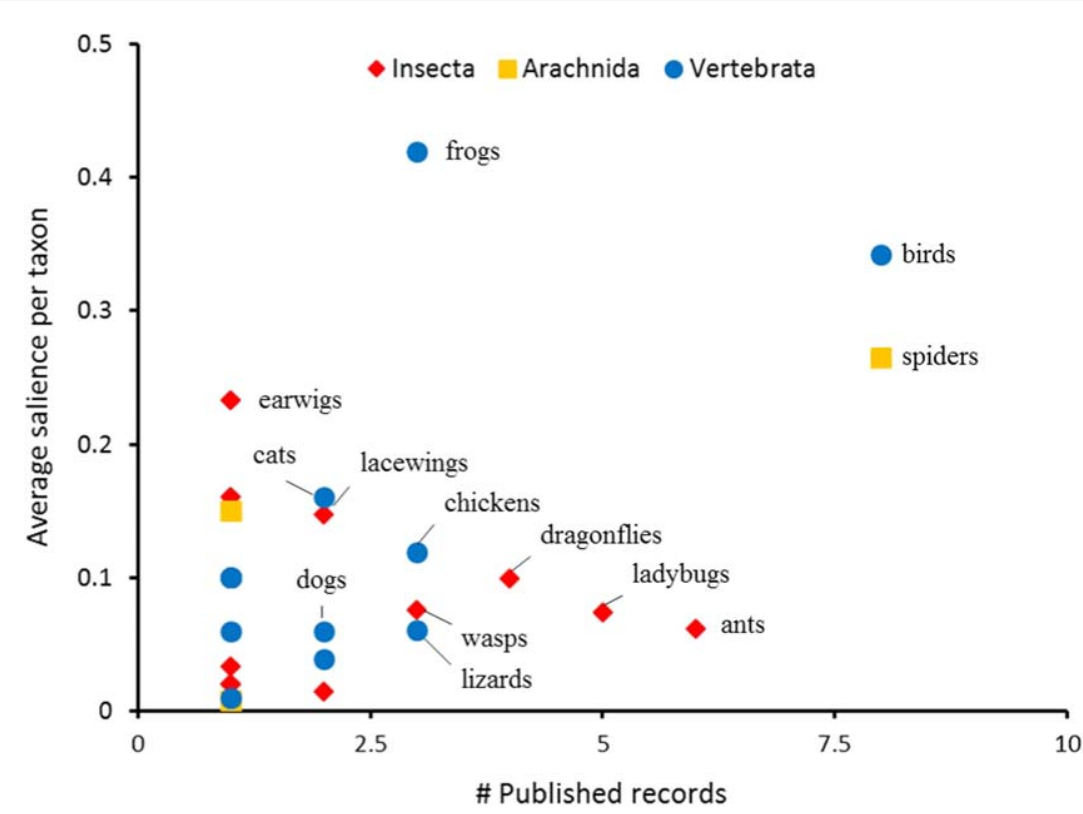

Figure 3. Large-bodied, diurnal and vertebrate natural enemies receive most attention from farmers. The graph depicts relative farmer awareness or 'salience' of vertebrate and invertebrate natural enemies, as compiled from farmers' free-listing of pest-killing organisms ( $n=13$ published studies). Natural enemy groups are organized by either class or sub-phylum. Salience is shown as the proportion of informants who listed a particular taxon, averaged across studies (with its respective number of published records shown on the $x$ axis). Extent of informant knowledge was gauged through free-listing, eventually complemented with photo-elicitation.

Average taxon-specific saliency was $28.0 \pm 19.4 \%$ ( $n=15$ studies), ranging from an average of $5.8 \%$ in Philippine rice producers that enumerated pests belonging to 4 arthropod orders (Litsinger et al 2009), to $78.8 \%$ in Indonesian rice farmers that listed pests belonging to 2 arthropod orders (Rubia et al 1996). 


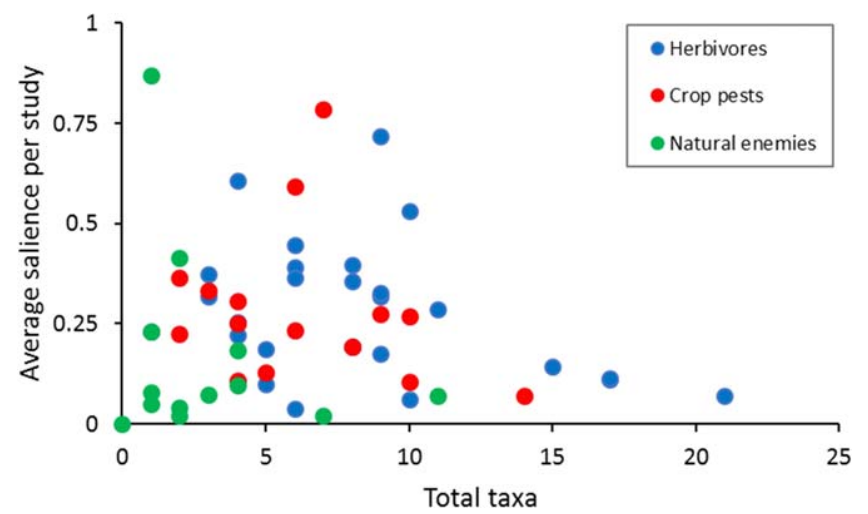

Figure 4. Farmers' knowledge of arthropod herbivores and pests is higher than that of beneficial (i.e. pest-killing) organisms. Farmers' ecological literacy is depicted for three groups of organisms of agricultural importance, i.e. herbivorous arthropods ( $n=27$ studies), economically-limiting pests $(n=15)$, and arthropod natural enemies $(n=13)$. Each dot on the scatterplot represents one single published study, in which average salience of farmer-listed arthropods is plotted against the total number of enumerated arthropod taxa, at a family-level taxonomic hierarchy. The graph reflects overall low levels of ecological literacy for natural enemies, and comparatively high literacy for herbivores and pests in cash crop systems. All datapoints originate from studies with present-day farmers.

\section{Farmers' understanding of beneficial insects and spiders}

A total of 13 studies documented farmers' knowledge of natural enemies, covering $2.7 \pm 2.5$ orders of arthropods and $1.2 \pm 1.6$ non-arthropod taxa. Arthropod natural enemies that were listed by farmers primarily belong to spiders (Araneae) (26.5 $\pm 35.3 \%$ farmers; $n=8$ studies), net-winged insects (Neuroptera) $(14.7 \pm 11.7 \% ; n=2)$ and beetles (Coleoptera) (7.3 $\pm 13.2 \% ; n=5$ studies) (figure 3 ). At the family level, relatively high saliency for lacewings (Chrysopidae) (14.7\%), ladybeetles (Coccinellidae) (7.3\%), wasps (Vespidae) (7.6\%) and praying mantids (Mantidae) $(1.4 \%)$ was reported in at least one study. Nonarthropod natural enemies that were commonly enumerated included birds (34.2\%; $n=8$ studies), frogs $(42.0 \% ; n=3)$ and cats $(16 \% ; n=2)$. For arthropods, average taxon-specific saliency was $16.5 \pm 24.0 \%$, ranging from an average of $5.7 \%$ amongst Honduran maize producers that either listed beetles, mantids, dragonflies, spiders or robber-flies as natural enemies (Wyckhuys and O’Neil 2007), to $87.0 \%$ in Philippine rice growers that recognized the role of spiders as natural enemies (Litsinger et al 2009).

\section{Ecological literacy and pest management practices}

At the finest taxonomic scale, ecological literacy encompassed $8.2 \pm 4.7$ herbivorous arthropods (average taxon-level salience $27.9 \pm 16.8 \% ; n=27$ studies), $6.3 \pm 3.4$ perceived target pests (salience $28.3 \pm 19.0 \% ; n=15)$ and $3.0 \pm 3.0$ natural enemies (salience $16.6 \pm 24.0 \% ; n=13$ ). Hence, across studies, an average farmer named 2.3 herbivorous arthropods, 1.8 target pests and 0.5 natural enemies. Ecological literacy did not differ between staple and cash/mixed cropping systems in terms of the total number or average saliency of listed herbivorous arthropods, perceived arthropod pests, or arthropod natural enemies (figure 4). When expanding analyses to include studies with less detailed entomological information, (as exclusively obtained through freelisting) similar trends were observed (table 1). For example, in a survey of well-educated European farmers with over 20 years of experience, $2.4 \pm 0.9$ agricultural pests and $1.4 \pm 0.6$ natural enemies were enumerated (Zhang et al 2018).

Approximately $70 \%$ farmers ( $n=17$ studies; 1088 informants) attributed high levels of importance to insect pests, signaling that pest attack regularly leads to e.g. production losses of $6 \mathrm{t} / \mathrm{ha}$ (Rubia et al 1996), yield losses up to 90\% (Munyuli et al 2017) and related economic impacts of over $\$ 400 /$ ha (Heong and Escalada 1999). Yet, only $47.5 \pm 25.0 \%$ farmers possessed moderate to good knowledge of the biology and morphology of key pests ( $n=4$ studies), and $38.3 \pm 18.0 \%$ of these had moderate to good knowledge of their ecology and feeding habits $(n=5$ studies). Though farmers' awareness of natural enemies and composite knowledge of biological control was low_rated 0.31 to 0.39 out of 1 (table 1), levels of awareness exhibited marginally significant differences between staple crops and cash/mixed systems (MannWhitney $U=19.00, p=0.052$; figure 5 ). In staple crop systems, $49.0 \pm 32.8 \%$ growers $(n=12$ literature records, 9 of which covering rice systems) were aware of the existence of natural enemies; as compared to $23.0 \pm 21.6 \% \quad(n=7) \quad$ in other agricultural systems.

On average, staple crop producers listed $75.8 \%$ more non-chemical pest management alternatives than those in mixed or cash crop systems. Pest management alternatives included mechanical and cultural approaches, diversification tactics, and to minor extent biological control (supplementary figure 3). Also, farmers' primary reliance upon synthetic pesticides for crop protection was significantly higher in 

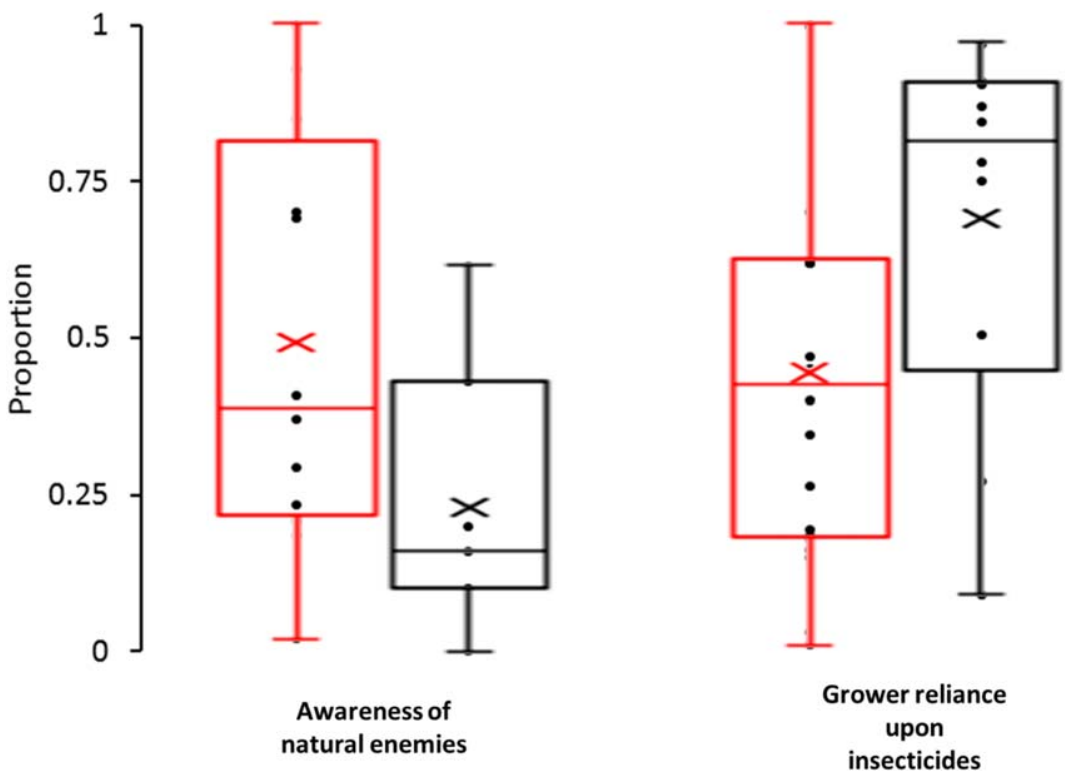

Figure 5. Agricultural systems with deficient ecological literacy can foster greater pesticide dependency. Farmers' awareness of 'pestconsuming' natural enemies and degree of reliance upon synthetic insecticides is contrasted between food staple (red) or cash crop/ mixed (black) systems. Both metrics are shown as the proportion of growers per study. Food staples include cereals, starchy tubers or roots, and pulses. Patterns are drawn from a total of 19 and 30 published studies respectively and are statistically significant at $p<0.10$ (Mann-Whitney U test; natural enemy awareness) and $p<0.05$ (ANOVA; insecticide reliance).

Table 1. Patterns in farmers' agro-ecological knowledge and associated pest management decision-making, as compiled from the global literature. Ecological knowledge is exclusively presented for studies that used free-listing (FL), while omitting those that relied upon photoelicitation, specimen description or snowball sampling. Patterns complement those for which in-depth entomological information is provided (as described in the text). Extent of usage of non-chemical alternatives reflects the proportion of farmers within a given study that employ other tactics than chemically-synthetized pesticides for crop protection.

\begin{tabular}{lccc}
\hline Informant knowledge/behavior & Average $( \pm$ SD) & $N$ \# studies (\#informants) & Geographical coverage \\
\hline Number of crop pests enumerated (FL) & $1.93 \pm 0.93$ & $28(2709)$ & $15(565)$ \\
Number of arthropod natural enemies (FL) & $0.92 \pm 0.69$ & $17(1088)$ & I, II, III, IV \\
Proportion of farmers reporting significant insect pest & $0.68 \pm 0.26$ & & I, II, III \\
$\quad$ damage (0-1) & & $19(1152)$ & I, II, III, IV \\
Awareness of natural enemies (0-1) & $0.39 \pm 0.31$ & $24(1536)$ & II, III, IV \\
Composite knowledge of insect biological control (0-1) & $0.31 \pm 0.21$ & $8(512)$ & II, III \\
Number of non-chemical measures listed per informant & $1.17 \pm 1.30$ & & I, II, III, IV \\
Extent of usage of non-chemical crop protection alter- & $0.24 \pm 0.22$ & & II, III, IV \\
$\quad$ natives (0-1) & & $30(1920)$ & II, III, IV
\end{tabular}

${ }^{a}$ I: Europe; II: Americas; III: Asia \& Oceania; IV: Africa.

cash $/$ mixed systems (ANOVA, $F_{1,28}=4.254, p$ $=0.049$ ) (figure 5). In the latter systems, on average $69.0 \pm 30.0 \%$ of farmers mainly relied on chemical options for pest management; $91.1 \%$ vegetable producers in Botswana mainly used synthetic pesticides (Obopile et al 2008). Across studies, farmers' dependency upon synthetic insecticides showed a (non-significant) downward trend with increasing ecological literacy and augmenting levels of technical knowledge (supplementary figure 4).

\section{Discussion}

We reveal high variability in agro-ecological knowledge between indigenous people of the tropics and western, industrial farmers, describe intermediate to high levels of ecological illiteracy among today's smallholders, and hint at its link to management decision-making. Anthropological studies with indigenous people reveal that they possess an advanced understanding of arthropods (e.g. Mali's Dogon enumerate 825 different organisms or ethno-categories, and name tens of species of dung beetle) as compared to present-day farmers. Yet, it is more common for ethnobiological studies to show that folk entomological knowledge is restricted to culturallyimportant or perceptually-salient organisms (Bentley 1992). At salience levels of $26 \%-28 \%$ for specific herbivores and pests, many farmers remain uninformed or indifferent about the identity of cropdamaging arthropods, though some $40 \%$ of them have 
certain understanding of their ecology and feeding habits, including their role in natural pest control (or 'biological control'). Biological control is conservatively valued at \$4.5-13.6 billion annually for US agriculture alone (Pimentel et al 1997, Losey and Vaughan 2006), and insect 'natural enemies' deliver pest control services worth hundreds of dollars ha ${ }^{-1}$ year $^{-1}$ in e.g. US corn, Thailand cassava or New Zealand cereals (Naranjo et al 2015, Sandhu et al 2015, Thancharoen et al 2018). Arthropod biological control can generate substantial farm-level savings that often surpass the local per-capita income (Kremen and Merenlender 2018), yet only a fraction of farmers recognize the existence of (on-farm) natural enemies. Instead, $52 \%$ of farmers refer to chemical insecticides as their primary means of pest control, with similar patterns among resource-poor farmers in the tropics and wealthier producers in Western countries. In the following, we discuss how a strengthening of ecological literacy can accelerate transitions to sustainable intensification, help produce residue-free food profitably and empower farmers as guardians of biodiversity.

Nearly 70\% of farmers (as surveyed in the screened literature) perceive arthropod pests as primary constraints to crop production yet possess restricted knowledge of them. In certain systems, any invertebrate creature is unwanted, while in others a 'pest' is solely an organism that inflicts economically-relevant crop damage (Morales and Perfecto 2000). Across our study, individual farmers were aware of 1.9 to 2.3 potential pests, out of an average 8.2 arthropod taxa per studied system (figures 2, 4). Our study revealed farmers' deficient understanding of pest biology and morphology, a weak link between causal agents and damage symptoms, confusion regarding the appearance of invasive pests, and often pervasive conflicting beliefs. The latter is illustrated by common folk beliefs that frogs grow out of bivalves (Ulicsni et al 2016), that mud wasps abduct children (Gurung 2003) or that caterpillar pests sprout from the plant (Wyckhuys and O'Neil 2007). This is aligned with techno-centric concepts of pest control (Morse and Buhler 1997), in which farmers lack a basic understanding and integrated perspective of herbivores as elements within a functioning ecosystem and are thus inclined to pursue curative measures for their mitigation, usually in the form of synthetic pesticides. Ecological literacy is particularly weak for small organisms such as mites, while knowledge of other crop antagonists, such as diseases, or soil fauna and nitrogen-fixing organisms may be even more limited (Pauli et al 2016). In rice ecosystems, herbivores make up $17 \%$ of the arthropod community and $1 \%$ of them are pests (as compared to $64 \%$ for natural enemies; Settle et al 1996), yet the bulk of farmers' actions are aimed at the prevention or control of the latter, instead of at conserving the more abundant beneficial organisms that naturally restrict pest proliferation.
Tribal people live in close association with nature and possess honed observation skills, but also have limited knowledge of certain invertebrates, e.g. gallmaking wasps. Their mind and overall reasoning is believed to have similar characteristics as the one of present-day farmers (Lévi-Strauss 1962), yet we record variable knowledge among geographies and cultures (supplementary figure 2) and superior ecological literacy as compared to farmers in developed societiesalthough this knowledge is not necessarily applied to agriculture. Such can be ascribed to the demise of indigenous communities and erosion of their knowledge (Brush 1993), or to the substituting effect of schooling (Reyes-García et al 2010), and also to agricultural 'deskilling' (Stone 2007). The loss of traditional pest management skills may have been triggered by the availability of standard (synthetic) pesticides and the development of a more industrialized agriculture centered on a limited set of commodity crops. As such, 'deskilling' and reliance on chemical pesticides can be mutually reinforcing, resulting in a 'lock-in' of chemical-based pest management (Flor et al 2019). The latter is hard to unlock because of path dependencies across the entire food system and strong positive feedback mechanisms, including the ability of a powerful agrochemical industry to influence policy (IPES 2016). Globally, farmers risk becoming passive customers of the agro-industry, in which a declining ecological literacy translates into an increased reliance on purchased synthetic inputs. 'Deskilling' can disrupt the balance between social and environmental learning, obstruct innovation processes and degrade farmers' ability to perform (Stone 2007). This may be most pronounced in settings with industrial styles of agriculture, as promoted through the 'green revolution'. However, it is important to realize that for some topics, such as insect ecology, local knowledge may never have been very deep in the first place.

Biological control is a central pillar of IPM, acting across geographies and agro-ecological contexts. Yet, in developed nations, it is often believed to be of minor importance (except for greenhouse systems, where it is increasingly adopted) and arable farmers regularly list their inability to effectively manage this ecosystem service as an impediment to further adoption (Zhang et al 2018). Identical trends are observed among smallholder farmers across the globe: up to $70 \%$ of growers are unaware of natural enemies or unfamiliar with the concept of biological control (table 1). Ecological literacy is shallow: farmers list $0.5-1$ natural enemy out of a mere 2-3 orders, primarily mentioning spiders, ants, wasps or ladybeetles. Disproportionate importance is ascribed to conspicuous, large-bodied, diurnal organisms and vertebrates (e.g. birds, frogs), in line with existing classification frameworks (Berlin 1992, Bentley 1992). This fractional recognition of biological control is long-standing, as reflected in the joint depiction of frogs and locusts within a 5000 year old Egyptian mastaba or in the ancient practice of weaver-ant 
conservation in Asia's fruit orchards. Yet, it occludes the role of e.g. more than 65000 chalcidoid and ichneumonoid parasitic wasps in pest control or the contribution of insect-killing fungi or nematodes. This deficient ecological literacy can hamper innovation, skew early adopters' decisions and stifle broader diffusion of ecologically-based practices (Catalini and Tucker 2017). On the contrary, a re-established or firmed appreciation of biological control can amend farmers' perception of pest risks and lower chemical dependency (figure 5), echoing findings from the across the globe (Abate et al 2000, Morales and Perfecto 2000). For instance, strengthening farmers' knowledge on pests and natural enemies in e.g. Farmer Field Schools or FFS has resulted in often substantial reductions of pesticide application (Winarto 2004, Pretty and Bharucha 2015). This underscores the intimate link between ecological literacy, farmer's pest management decisions and broader environmental impacts.

Psychological, socio-economic and environmental factors all affect farmers' pest management behavior (Mills et al 2017, Zhang et al 2018). Habitually, decisions to apply pesticides are not based on economic rationale, but instead guided by 'worst case' scenarios, molded by loss aversion, shaped by peer pressure or triggered through marketing campaigns by agrochemical suppliers (Heong and Escalada 1999, LaCanne and Lundgren 2018). Farmers' continued reliance upon pesticides may seem irrational in light of secondary pest outbreaks, declining returns, questionable productivity gains, food safety concerns or increasing pest resistance (Jørgensen et al 2018). Yet, it can also reflect a 'cognitive handicap' that pulls farmers away from ecologically-based options such as biological control and reinforces their dependency upon chemical solutions (Huang et al 2018). To remediate the above, deliberate efforts are required to measure and monetize insect biological control, internalize its benefits in farming operations, and duly communicate those to growers (Naranjo et al 2015, Sandhu et al 2015). Regulatory frameworks also need to be adapted - especially in developing countries-as to prevent pesticides from being sold as 'fast moving consumer goods'.

Participatory approaches such as FFS or China's Science and Technology Backyard (STB) platforms engage farmers in observation-based learning and boost their ability to recognize natural enemies and value biological control services (Pretty et al 2018). Schemes have also been designed to strengthen social capital, maximize inter-personal knowledge transfer and stimulate farmers' individual or collective innovative capacity (Schut et al 2014). To advance these initiatives, one option to consider is re-routing a fraction of the world's $1 / 2$ trillion dollar annually in agricultural subsidies to agro-ecological education, awareness-raising and interpersonal practice-sharing
(De Snoo et al 2013, Poore and Nemecek 2018), and to actively pursue reforms in pesticide regulation.

Agricultural research in the developing world may equally have to adapt to meet the Anthropocene challenges: overall, research has to become sufficiently anchored in the needs and priorities of farmers (Altieri 2004, Geertsema et al 2016), take into account their management style to enable capitalizing on farmers' innovativeness (Brodt et al 2004, Cui et al 2018), go to greater lengths in bolstering their adaptive capacity, propose ecological principles instead of 'ready-made' recipes (Šūmane et al 2018), and transition towards more effective nodular, decentralized structures (MacMillan and Benton 2014). By doing so, farmers can fully take part in a virtuous cycle of adaptive co-design of resource-efficient and revenue-generating agricultural practices. Indeed, farmers are 'born experimenters', have an exceptional capacity for innovation and ability to mold farming techniques to variable, unpredictable and risk-prone environments (Chambers et al 1989). Helping farmers rediscover the 'things that matter' can put them in a lead position to preserve our common heritage, drive agricultural transitions and tackle several of the Anthropocene challenges.

\section{Acknowledgments}

This research did not receive any specific grant from funding agencies in the public, commercial, or notfor-profit sectors. Publication charges were covered through Zhejiang Provincial Key R\&D project 2019C04007. The authors are grateful to three anonymous reviewers that helped improve an earlier draft of the manuscript.

\section{Data availability}

The data that support the findings of this study are available from the corresponding author upon reasonable request.

\section{Conflict of interest}

The authors report no conflict of interest.

\section{Author contributions}

KAGW conceived and designed the experiments; KAGW analyzed the data; all authors co-wrote the paper.

\section{ORCID iDs}

KA G Wyckhuys (iD https://orcid.org/0000-00030922-488X 


\section{References}

Abang A F, Kouamé C M, Abang M, Hanna R and Fotso A K 2014 Assessing vegetable farmer knowledge of diseases and insect pests of vegetable and management practices under tropical conditions Int. J. Vegetable Sci. 20 240-53

Abate T, van Huis A and Ampofo J K O 2000 Pest management strategies in traditional agriculture: an African perspective Annu. Rev. Entomol. 45 631-59

Altieri M A 2004 Linking ecologists and traditional farmers in the search for sustainable agriculture Frontiers Ecol. Environ. 2 35-42

Atteh O D 1984 Nigerian farmers' perception of pests and pesticides Int. J. Trop. Insect Sci. 5213-20

Bentley J W 1992 Alternatives to pesticides in Central America: applied studies of local knowledge Cult. Agric. 12 10-3

Bentley J W 1993 What Farmers do not know Ceres 26 42-5

Bentley J W and Rodríguez G 2001 Honduran folk entomology Curr. Anthropol. 42 285-301

Berkes F, Colding J and Folke C 2008 Navigating Social-Ecological Systems: Building Resilience for Complexity and Change (Cambridge: Cambridge University Press)

Berlin B 1992 Ethnobiological Classification: Principles of Categorization (Princeton, NJ: Princeton University Press)

Bernhardt E S, Rosi E J and Gessner M O 2017 Synthetic chemicals as agents of global change Frontiers Ecol. Environ. 15 84-90

Brodt S, Klonsky K, Tourte L, Duncan R, Hendricks L, Ohmart C and Verdegaal P 2004 Influence of farm management style on adoption of biologically integrated farming practices in California Renew. Agric. Food Syst. 19 237-47

Brush S B 1993 Indigenous knowledge of biological resources and intellectual property rights: the role of anthropology $\mathrm{Am}$. Anthropol. 95 653-71

Catalini C and Tucker C 2017 When early adopters do not adopt Science 357 135-6

Chambers R, Pacey A and Thrupp L A 1989 Farmer First: Farmer Innovation and Agricultural Research (London: Intermediate Technology Publishers)

Cui Z et al 2018 Pursuing sustainable productivity with millions of smallholder farmers Nature 555 363-6

De Snoo G R et al 2013 Toward effective nature conservation on farmland: making farmers matter Conservation Lett. 6 66-72

Deutsch C A, Tewksbury J J, Tigchelaar M, Battisti D S, Merrill S C, Huey R B and Naylor R L 2018 Increase in crop losses to insect pests in a warming climate Science $361916-9$

DeWalt B R 1994 Using indigenous knowledge to improve agriculture and natural resource management Hum. Organ. $53123-31$

Ehler E L 2006 Integrated pest management (IPM): definition, historical development and implementation, and the other IPM Pest Manage. Sci. 62 787-9

Flandroy L et al 2018 The impact of human activities and lifestyles on the interlinked microbiota and health of humans and of ecosystems Sci. Total Environ. 627 1018-38

Flor R J, Maat H, Hadi B A R, Kumar V and Castilla N 2019 Do fieldlevel practices of Cambodian farmers prompt a pesticide lock-in? Field Crop Res. 235 68-78

Geertsema W, Rossing W A, Landis D A, Bianchi F J J A, Van Rijn P C, Schaminée J H, Tscharntke T and Van Der WerfW 2016 Actionable knowledge for ecological intensification of agriculture Frontiers Ecol. Environ. 14 209-16

Griaule M 1961 Classification des insectes chez les Dogon J. Afr. 31 $7-7$

Gurung A B 2003 Insects-a mistake in God's creation? Tharu farmers' perception and knowledge of insects: a case study of Gobardiha Village Development Committee, DangDeukhuri, Nepal Agric. Hum. Values $20337-70$

Heong K L and Escalada M M 1999 Quantifying rice farmers' pest management decisions: beliefs and subjective norms in stem borer control Crop Prot. 18 315-22
Huang J, Zhou K, Zhang W, Deng X, van der Werf W, Lu Y, Wu K and Rosegrant M 2018 Uncovering the economic value of natural enemies and true costs of chemical insecticides to cotton farmers in China Environ. Res. Lett. 13064027

IPES 2016 From Uniformity to Diversity: A Paradigm Shift From Industrial Agriculture to Diversified Agroecological Systems. International Panel of Experts on Sustainable Food Systems (Louvain-la-Neuve, Belgium: IPES)

Isbell F et al 2017 Linking the influence and dependence of people on biodiversity across scales Nature 546 65-72

Jørgensen P S et al 2018 Antibiotic and pesticide susceptibility and the Anthropocene operating space Nat. Sustain. 1 632-41

Krebs J R, Wilson J D, Bradbury R B and Siriwardena G M 1999 The second silent spring? Nature $400611-2$

Kremen C and Merenlender A M 2018 Landscapes that work for biodiversity and people Science 362 eaau6020

LaCanne C E and Lundgren J G 2018 Regenerative agriculture: merging farming and natural resource conservation profitably Peer J. 6 e 4428

Lamarque P, Meyfroidt P, Nettier B and Lavorel S 2014 How ecosystem services knowledge and values influence farmers' decision-making PLoS One 9 1-16

Lechenet M, Dessaint F, Py G, Makowski D and Munier-Jolain N 2017 Reducing pesticide use while preserving crop productivity and profitability on arable farms Nat. Plants 3 17008

Lévi-Strauss C 1962 La Pensée Sauvage (Paris: Plon)

Litsinger J A, Libetario E M and Canapi B L 2009 Eliciting farmer knowledge, attitudes, and practices in the development of integrated pest management programs for rice in Asia Integrated Pest Management: Dissemination and Impact (Dordrecht: Springer) pp 119-273

Losey J and Vaughan M 2006 The economic value of ecological services provided by insects BioScience 56 311-23

MacMillan T and Benton T G 2014 Engage farmers in research Nature 509 25-6

Maxwell S L, Fuller R A, Brooks T M and Watson J E 2016 Biodiversity: the ravages of guns, nets and bulldozers Nature 536 143-5

Miller A 1983 The influence of personal biases on environmental problem-solving J. Environ. Manage. 17 133-42

Mills J, Gaskell P, Ingram J, Dwyer J, Reed M and Short C 2017 Engaging farmers in environmental management through a better understanding of behaviour Agric. Hum. Values 34 283-99

Morales $\mathrm{H}$ and Perfecto I 2000 Traditional knowledge and pest management in the Guatemalan highlands Agric. Hum. Values 17 49-63

Morse S and Buhler W 1997 Integrated Pest Management: Ideals and Realities in Developing Countries (London: Lynne Riener Publishers)

Munyuli T et al 2017 Farmers' perceptions, believes, knowledge and management practices of potato pests in South-Kivu Province, eastern of Democratic Republic of Congo Open Agric. 2362-85

Naranjo S E, Ellsworth P C and Frisvold G B 2015 Economic value of biological control in integrated pest management of managed plant systems Annu. Rev. Entomol. 60 621-45

Obopile M, Munthali D C and Matilo B 2008 Farmers' knowledge, perceptions and management of vegetable pests and diseases in Botswana Crop Prot. 27 1220-4

Oerke J 2005 Crop losses to pests J. Agric. Sci. 14431-43

Oliver T H, Isaac N J, August T A, Woodcock B A, Roy D B and Bullock J M 2015 Declining resilience of ecosystem functions under biodiversity loss Nat. Commun. 610122

Pauli N, Abbott L K, Negrete-Yankelevich S and Andrés P 2016 Farmers' knowledge and use of soil fauna in agriculture: a worldwide review Ecol. Soc. 2119

Petiza S, Hamada N, Bruno A C and Costa-Neto E M 2013 Etnoentomología baniwa Boletín Soc. Entomol. Aragonesa 52 323-43 
Pimentel D, Wilson C, McCullum C, Huang R, Dwen P, Flack J, Tran Q, Saltman T and Cliff B 1997 Economic and environmental benefits of biodiversity Bio. Sci. 47 747-57

Poore J and Nemecek T 2018 Reducing food's environmental impacts through producers and consumers Science 360 987-92

Posey D A 1984 Hierarchy and utility in a folk biological taxonomic system: patterns in classification of arthropods by the Kayapó Indians of Brazil J. Ethnobiol. 4 123-39

Pretty J et al 2018 Global assessment of agricultural system redesign for sustainable intensification Nat. Sustain. 1441-6

Pretty J and Bharucha Z 2015 Integrated pest management for sustainable intensification of agriculture in Asia and Africa Insects 6 152-82

Reyes-García V, Kightley E, Ruiz-Mallén I, Fuentes-Peláez N, Demps K, Huanca T and Martínez-Rodríguez M R 2010 Schooling and local environmental knowledge: do they complement or substitute each other? Int. J. Educ. Dev. 30 305-13

Rubia E G, Lazaro A A, Heong K L, Diah N and Norton G A 1996 Farmers' perceptions of the white stem borer Scirpophaga innotata (Walker), in Cilamaya, West Java, Indonesia Crop Prot. 4327-33

Russell B 2002 Research Methods in Anthropology: Qualitative and Quantitative Approaches (Altamira, New York: Rowman \& Littlefield)

Sandhu H, Wratten S, Costanza R, Pretty J, Porter J R and Reganold $\mathrm{J} 2015$ Significance and value of non-traded ecosystem services on farmland Peer. J. 3 e762

Schut M, Rodenburg J, Klerkx L, van Ast A and Bastiaans L 2014 Systems approaches to innovation in crop protection. A systematic literature review Crop Prot. 56 98-108

Settle W H, Ariawan H, Astuti E T, Cahyana W, Hakim A L, Hindayana D and Lestari A S 1996 Managing tropical rice pests through conservation of generalist natural enemies and alternative prey Ecology 77 1975-88

Smith H F and Sullivan C A 2014 Ecosystem services within agricultural landscapes-Farmers' perceptions Ecol. Econ. 98 72-80

Stafford-Smith M, Griggs D, Gaffney O, Ullah F, Reyers B, Kanie N, Stigson B, Shrivastava P, Leach M and O'Connell D 2017
Integration: the key to implementing the Sustainable Development Goals Sustain. Sci. 12 911-9

Stone G D 2007 Agricultural deskilling and the spread of genetically modified cotton in Warangal Curr. Anthropol. 48 67-103

Stork N E 2018 How many species of insects and other terrestrial arthropods are there on Earth? Annu. Rev. Entomol. 63 31-45

Šūmane S, Kunda I, Knickel K, Strauss A, Tisenkopfs T, des Ios Rios I, Rivera M, Chebach T and Ashkenazy A 2018 Local and farmers' knowledge matters! How integrating informal and formal knowledge enhances sustainable and resilient agriculture J. Rural Stud. 59 232-41

Sánchez-Bayo F and Wyckhuys K A G 2019 Worldwide decline of the entomofauna: a review of its drivers Biol. Conservation $2328-27$

Thancharoen A, Lankaew S, moonjuntha P, Wongphanuwat T, Sangtongpraow B, Ngoenklan R, Kittipadakul P and Wyckhuys K A G 2018 Effective biological control of an invasive mealybug pest enhances root yield in cassava J. Pest Sci. $911199-211$

Teixeira H M, Vermue A J, Cardoso I M, Claros M P and Bianchi FJ J A 2018 Farmers show complex and contrasting perceptions on ecosystem services and their management Ecosyst. Serv. 33 44-58

Ulicsni V, Svanberg I and Molnár Z 2016 Folk knowledge of invertebrates in Central Europe-folk taxonomy, nomenclature, medicinal and other uses, folklore, and nature conservation J. Ethnobiol. Ethnomed. 1247

Van Mele P 2008 The importance of ecological and sociotechnological literacy in $R \& D$ priority setting: the case of a fruit innovation system in Guinea, West Africa Int. J. Agric. Sustain. 6 183-94

Winarto Y T 2004 Seeds of Knowledge: the Beginning of Integrated pest Management in Java (New Haven, US: Yale University Southeast Asia Studies) (https://doi.org/10.3763/ ijas.2008.0369)

Wyckhuys K A G and O'Neil R J 2007 Local agro-ecological knowledge and its relationship to farmers' pest management decision making in rural Honduras Agric. Hum. Values 24 307-21

Zhang H, Potts S G, Breeze T and Bailey A 2018 European farmers' incentives to promote natural pest control service in arable fields Land Use Policy 78 682-90 